\title{
A PLANTA DA INFÂNCIA EM LAVOURA ARCAICA, DE RADUAN NASSAR*
}

Iza QUELHAS (Universidade do Estado do Rio de Janeiro) quel.iza@uol.com.br

Resumo: Este artigo focaliza as relações entre literatura, identidades e culturas, a partir da leitura do romance Lavoura arcaica (1975), de Raduan Nassar. Narrado em primeira pessoa, destacam-se a linguagem lírica e a forma romanesca marcadas pela interpenetração de gêneros - lírico, épico, dramático -, propiciando aos leitores a vivência da tensão entre a diegese e o modo de narrar.

Palavras-chave: Lavoura arcaica. Raduan Nassar. Literatura Brasileira. Romance. Lirismo.

\section{THE TREE OF CHILDHOOD IN LAVOURA ARCAICA, BY RADUAN NASSAR}

\begin{abstract}
This article focuses on the relations between literature, identities and cultures, based on the reading of the novel Lavoura Arcaica (1975), by Raduan Nassar. It is narrated in the first person, the lyric language and the Romanesque style are marked by the genre interpenetration - lyric, epic and dramatic -, which enable the readers to experience the friction between the diegesis and the narrative mode.
\end{abstract}

Key-words: Lavoura arcaica. Raduan Nassar. Brazilian literature. Romance. Lyricism. 


\section{Breve introdução}

Neste artigo, mobiliza-se o caminho aberto por Severo Sarduy (s/d), principalmente, cuja busca pela potencialidade estética não encontra nem almeja a escrita representativa. Trata-se, portanto, de nossa hipótese de leitura: a refutação da escrita representativa sustenta a singularidade do romance Lavoura arcaica (NASSAR, 1999).

Severo Sarduy, nascido em Cuba, em 1937, faleceu em Paris, em 1993, foi poeta, romancista, crítico e jornalista. É de sua autoria o termo neobarroco, datado em 1972. Destaca o autor que o neobarroco não pressupõe uma vanguarda, pois se apropria de fórmulas anteriores e dá um novo sentido e direção ao soneto, à novela e ao romance. Este último, tal como registramos neste artigo, coloca em relevo a linguagem e a exploração dos significados em gêneros que se interpenetram. Por outro caminho, tem-se Antonin Artaud (18961948) que afirmou um teatro que seria capaz de uma "poesia atroz" (ARTAUD, 2006, p. 3). Tal poesia atroz poderia nos resguardar de uma vida em que "falta enxofre" (Idem). A falta de enxofre leia-se como ausência de magia e encantamento, indispensáveis, segundo Artaud, numa vida significativa.

Para a crítica e a historiografia literária um dos grandes desafios é o de identificar o que é literatura contemporânea. Seguindo a concepção proposta por Nietzsche e Giorgio Agamben, Karl Erik Scholllamer afirma:

O contemporâneo é aquele que, graças a uma diferença, a uma defasagem ou um anacronismo, é capaz de captar seu tempo e enxergá-lo. Por não se identificar, por sentirse em desconexão com o presente, cria um ângulo do qual é possível expressá-lo (SCHOLLHAMMER, 2009, p. 9-10)

É desse ângulo que, supostamente Raduan Nassar, em Lavoura arcaica (1975), expressa sua desconexão com o presente e insere seu romance entre as grandes obras que permanecem. Raduan Nassar (1935, Pindorama, São Paulo), filho de imigrantes libaneses, cresceu no interior paulistano, formando-se em Filosofia, em São Paulo. Em 1978, Nassar publicou a novela Um copo de cólera; em 1997, Menina a caminho, livro composto por contos escritos nas décadas de sessenta e setenta.

Lavoura arcaica, apesar de uma recepção crítica muito elogiosa, não encontra um lugar na linha da tradição literária que vinha se consolidando ao 
longo dos vários momentos do Modernismo. Nem toda a crítica foi elogiosa, conforme registra Jacqueline Ribeiro de Souza, em sua dissertação de mestrado intitulada Discurso e subjetividade em Lavoura arcaica de Raduan Nassar. Alguns críticos refutaram as qualidades da obra, questionando o lugar desse romance na literatura brasileira (SOUZA, 2013, p. 22).

$\mathrm{Na}$ década de setenta, principalmente, a crítica literária reconhece muito mais a diversidade de tendências e correntes na literatura brasileira, sendo pouco produtivos, até o momento, os esforços para um mapeamento de produção tão vasta. Clarice Lispector e Guimarães Rosa permanecem, por muitas décadas, referências autorais decisivas para a compreensão da prosa de fiç̧ão brasileira. Os contos de Rubem Fonseca, principalmente, trariam o destaque dado ao "realismo brutalista", nas palavras de Bosi (1999) e de Antonio Candido (1989), que abre caminho para uma ficção mais concisa em seu realismo que recorta da realidade o mínimo efeito que produz a linguagem quase descarnada dessa literatura. Na poesia, as diferenças separavam, de um lado, os poetas atentos à "escavação do real", na poesia de Carlos Drummond de Andrade, por exemplo; de outro, a poesia que explorou simbolismos católicos, experimentalismos surrealistas, o inconsciente e o mistério que marcariam a obra de Jorge de Lima, tão admirado por Raduan Nassar.

Por sua vez, ao longo das décadas seguintes até a atualidade, a historiografia literária procura os sucessores da obra nassariana, na tentativa de abrir caminhos pelo atalho de uma visionária potencialidade da fiç̧ão à "abertura às nossas diferenças" (BOSI, 1999, p. 437). Alfredo Bosi menciona Raduan Nassar comparando sua prosa a de Milton Hatoum e Carlos Sussekind; outros críticos identificam similaridades com a experimentação da linguagem ficcional de Osman Lins.

Nas palavras de Flora Süssekind, a trilha narrativa proposta pelo romance Lavoura arcaica retoma, de forma inovadora, a "história do filho pródigo": "estamos sempre indo para casa", como afirma o protagonista (SUSSEKIND, 2004, p. 110-111). Nessa linhagem temática - a parábola do filho pródigo - há consistente fortuna crítica. 


\section{1. À flor da água}

O romance Lavoura arcaica foi escrito num momento em que o país se fortalecia como nação moderna e capitalista, resguardado um cenário social de agudas desigualdades. $\mathrm{O}$ crescimento econômico desse período (quase dez por cento ao ano) atraiu para as cidades multidões de trabalhadores rurais, esvaziando o espaço interiorano, num período político e econômico complexo, pós-golpe militar de sessenta e quatro.

O quadro cultural, social e econômico acentua o anacronismo da história vivida pelas personagens, destacando-se, num período denominado por parte da crítica literária de "pós-moderno". O espaço de uma lavoura, mantida nos limites de princípios arcaicos, aproxima o romance do texto bíblico com a qual estabelece intensa intertextualidade. Tais questões destacam ainda mais o romance Lavoura arcaica, publicado em meados da década de setenta, em plena ditadura militar - o "milagre econômico" -, marcado pela repressão e pela censura.

A estrutura do romance apresenta uma divisão em capítulos numerados, de 1 a 30, que abarcam as duas grandes partes da história narrada: "A partida" e "O retorno". Em "A partida", a epígrafe é extraída de um poema intitulado "O céu jamais me dê a tentação funesta", do livro A invenção de Orfeu (1952), do poeta brasileiro Jorge de Lima: "Que culpa temos nós dessa planta da infância, de sua sedução, de seu viço e constância?" (NASSAR, 1999, p. 7). A epígrafe desloca o olhar para a produção poética de Jorge de Lima, cujas afinidades com a linguagem lírica e o enredo de Lavoura arcaica serão evidenciadas mais adiante. Considera-se relevante o que diz Alfredo Bosi, ao comentar a poesia de Jorge de Lima que empreende uma "descida às fontes da memória e do inconsciente", pelo "sentimento do sagrado" que "vive à flor da água" (BOSI, 1999, p. 452) e se mistura ao gosto da terra, testemunha ancestral das histórias contadas um dia, da fala e da escrita que se aproximam mais do que se distanciam. Bosi observa em relação à Lavoura arcaica: "um romance intimista cujo trabalho formal levou a linguagem às fronteiras da prosa poética" (Idem, p. 423)

$\mathrm{Na}$ segunda parte do romance intitulada "O retorno", a epígrafe selecionada é do Alcorão, Surata IV, 23, livro da tradição religiosa, das mais antigas, que 
afirma: "Vos são interditadas: vossas mães, vossas filhas, vossas irmãs, (...)" (NASSAR, 1999, p. 145).

Abre-se a narrativa com um trecho literário no qual a imagem da infância emerge poderosa pela sugestiva tensão entre os graus de liberdade, tanto poética quanto cultural; depois, na segunda parte, a abertura é feita por um fragmento textual da linha da tradição, assim como afirma o imperativo da interdição, o que talvez funcione como uma prolepse do desfecho trágico. Infância e interdição constituem a matéria-prima desse romance que trata de forma lírica e erótica as relações humanas.

\subsection{O trabalho e a desmesura}

No texto romanesco, sobressai o erotismo no jogo com o objeto perdido (o amor de Ana, o amor da mãe), enfatiza o lúdico das relações e parodia numa transgressão do útil e do diálogo natural dos corpos (SARDUY, s/d). Eis a atmosfera do barroco: não se prioriza o útil e o estético é indispensável. Enquanto a obra clássica, com sua variedade na unidade de suas manifestações, coloca em cena o trabalho e o culto ao aprimoramento incessante da forma, a obra no barroco aponta a linguagem como desmesura, como repetição do suplemento. Tal leitura inovadora proposta por Nassar, em sua prosa ficcional, principalmente Lavoura arcaica, mobiliza esta proposta investigativa no caminho aberto por Severo Sarduy (s/d), principalmente. Focaliza-se, neste artigo, a busca pelo modo como se configura a potencialidade estética que não se pretende escrita representativa, assumindo um lugar inovador e instigante. Trata-se do "jogo envolvendo uma ação narrativa reduzida quase ao ponto zero, (...) um aumento vertiginoso dos parênteses, de falas que se sucedem quase sem parágrafos, vazios e intervalos capazes de torná-las menos abafadas, de palavras que se multiplicam torrencialmente" (SARDUY, s/d, p. 111). No modo de narrar sobressai o movimento que configura a elipse, prevalece uma arte da "deposição e da discussão", sinalizando o foco político da estética barroca e neobarroca: a "contestação da própria ordem que até aí o estruturava com o seu afastamento e a sua autoridade; barroco onde se recusa qualquer instauração, onde o que se metaforiza é o fato de a ordem ser discutida, o deus julgado, a lei transgredida. Barroco da Revolução" (Idem, p. 94-97). 
$\mathrm{Na}$ linguagem em prosa ficcional, a elipse é importante para que se possa compreender o movimento da velocidade na narrativa, constituindo "toda a forma de supressão de lapsos temporais mais ou menos alargados, supressão essa que é denunciada de modo variavelmente transparente" (REIS; LOPES, 1996, p. 119121). A elipse pode associar-se, metaforicamente, a uma "amputação de elementos discursivos suscetíveis de serem recuperados pelo contexto" (Idem, p. 119). Vislumbra-se na narrativa, em fluxo crescente, a predominância da função modalizante, o cambiar de sentimentos em relação aos acontecimentos narrados, obscurece o ato de julgar ou avaliar.

André, um dos sete filhos de pais que formam uma família marcada pelos contrastes, assinala as diferenças entre aqueles que se vinculam à linha paterna, o irmão Pedro, Rosa, Zuleika e Huda, um exército posicionado à direita para continuar a tradição familiar, enquanto Ana, Lula e o próprio narrador, posicionados à esquerda, aproximam-se à figura materna associada a uma "anomalia":

(...) já o da esquerda trazia o estigma de uma cicatriz, como se a mãe, que era por onde começava o segundo galho, fosse uma anomalia, uma protuberância mórbida, um enxerto junto ao tronco talvez funesto, pela carga de afeto; podia-se quem sabe dizer que a distribuição dos lugares na mesa (eram caprichos do tempo) definia as duas linhas da família (NASSAR, 1999, p. 156-157).

Quando Pedro o encontra na pensão, é um André transfigurado que afirma "eu sou um epiléptico" (Idem, p. 41) e derrama o "jarro" de sua "velha identidade" (Idem, p. 41), enfileirando-se entre os que julgam a doença uma maldição. Identifica-se, portanto, no drama da identidade rechaçada, primeiro internamente pelo próprio André, depois pela assunção da perspectiva do outro (o pai, o irmão mais velho), o preconceito.

A mãe, cujo amor por André inaugura o erótico nas cenas de intimidade doméstica, é apresentada por um narrador que aproxima em sugestivas semelhanças mãe e irmã; com Lula, o irmão mais novo, as semelhanças com Ana. Instaura-se um movimento circular em torno de um centro anômalo - a figura materna - no contexto da ordem patriarcal:

(...) e era então um jogo sutil que nossas mãos compunham debaixo dos lençóis, e eu ria e ela cheia de amor me asseverava num cicio 'não acorda teus irmãos, coração', e ela depois erguia minha cabeça contra a almofada quente do seu ventre e, curvando o corpo grosso, beijava muitas vezes meus cabelos (...) (NASSAR, 1999, p. 27). 
A narração dos gestos maternos cotidianos - um jogo sutil composto pelas mãos da mãe e do filho sob os lençóis - e a sensualidade mútua unem-se, sem pausa, à descrição de elementos religiosos, na cena em que se insere uma frágil inocência do narrador personagem. A infância é vista na dimensão metafórica de uma planta que estende suas raízes transtornadas naquele que revive a força de Eros no contexto interdito da família.

\subsection{A petulante decadência}

O retorno de André culmina num evento - a festa familiar que comemora a Páscoa e o retorno do filho que se afastara durante tanto tempo -; no decorrer desse evento, Ana irrompe no círculo e dança sua "petulante decadência", confronta, num cenário de abundância sonora, visual, olfativa e táctil - os passos, a flauta, as palmas, os risos - a autoridade paterna. O ápice da ação e de tensão dramática, definido pela dança da irmã, denuncia a paixão correspondida de Ana por André, provoca no protagonista, que a tudo assiste num lugar afastado, um sentimento de perda e uma lucidez extrema, configurado na imagem de um corpo com "partes amputadas".

André procura, em vão, sua antiga (e improvável) unidade, instaurando-se o trágico no momento festivo da narrativa. A festa e a dança potencializam antigas tradições. As festas de culto agrário, segundo estudiosos, foram o "culto religioso a Dioniso" e este culto "deu origem à tragédia", cujo termo, tragos, designa o "bode expiatório dos sacrifícios realizados no ritual de Dioniso" (BRUNO, 2004, p. 8). Em vários momentos da narrativa, André se descreve como alguém cuja vida angustiada distancia-o da severa educação e exemplaridade paterna. A vida errante aproxima-o também a Dioniso, cujo "reino não tinha sede" (Idem).

Durante a festa, Ana se apresenta vestida de forma inusitada; Pedro, temeroso, conta ao pai o segredo de André: o amor pela irmã. Abalado com a gravidade da revelação, o pai mata a filha, enquanto ela, a bailarina, dança ao som da flauta, embalada por palmas e risos daqueles que a cercam e celebram, sem o saber ainda, o sacrifício de um cordeiro que assume as cores e as roupas de mulheres tidas como "pecadoras". Se, inicialmente, a própria mãe chama André de "meu cordeiro", Ana, numa súbita e silenciosa provocação, convoca a 
fúria do pai, direciona-a para sua própria ousadia: ela, a dançarina, para sempre proibida ao irmão.

(...) ela sabia surpreender, essa minha irmã, sabia molhar a sua dança, embeber a sua carne, castigar a minha língua no mel litúrgico daquele favo, me atirando sem piedade numa insólita embriaguez, me pondo convulso e antecedente, me fazendo ver com espantosa lucidez as minhas pernas de um lado, os braços de outro, todas as minhas partes amputadas se procurando na antiga unidade do meu corpo (eu me reconstruía nessa busca! que salmoura nas minhas chagas, (...) (NASSAR, 1999, p. 190).

A força de Ana, com sua dança inscrita em contexto familiar, revela-se em rebeldia em relação à autoridade paterna. O que transborda em Ana e em sua dança é o que Artaud chama Encantamento. A dança, nessa concepção, é linguagem.

(...) fazer a metafísica da linguagem articulada é fazer com que a linguagem sirva para expressar aquilo que habitualmente ela não expressa: é usá-la de um modo novo, excepcional e incomum, é devolver-Ihe suas possibilidades de comoção física, é dividi-la e distribuí-la ativamente no espaço, é tomar as entonações de uma maneira concreta absoluta e devolver-lhes o poder que teriam de dilacerar e manifestar realmente alguma coisa, é voltar-se contra a linguagem e suas fontes rasteiramente utilitárias, poder-se-ia dizer alimentares, contra suas origens de animal acuado, é enfim, considerar a linguagem sob a forma do Encantamento (ARTAUD, 2006, p. 46-47).

Se o lirismo rasura a prosa de ficção, a dança de Ana atravessa o espaço familiar e inaugura o movimento que diz o que calou ao longo de toda a narrativa. O corpo e os movimentos de Ana são guiados por esse Encantamento que Artaud busca no teatro.

O encanto sugerido pelo acionamento da audição - a música que conduz a dança - destaca a persuasão da palavra, da voz, da melodia dos versos, dos instrumentos musicais, confere à oralidade uma força capaz de tornar o ausente presente - o valor da encenação, como diz Artaud (Idem).

$\mathrm{Na}$ diegese, o tema do tempo torna-se uma qualidade - a paciência. Uma virtude nas culturas cristãs, como se depreende dos ensinamentos paternos. $O$ modo de narrar enfatiza a organização diegética, os acontecimentos são dispostos e recusam linearidades, há adiamentos de informações preciosas para a compreensão da história, o discurso, quase ininterrupto do narrador, destaca que é ele o detentor do poder.

A figura paterna, num contexto que tanto pode ser o de uma aldeia no mediterrâneo, quanto o de uma pequena cidade no interior do Brasil, atualiza um enfrentamento de forças assimétricas: a obliquidade das palavras, das ações e 
dos temas ligados à semântica da ordem afetiva e cultural imposta desde a infância.

A seguir transcrevem-se algumas passagens do romance nas quais são retomados trechos anteriores, repetição de passagens inteiras, com outras sequências, num movimento espiralado, que retorna a um momento anterior para ampliá-lo e não explicá-lo. Nos trechos transcritos a seguir, os negritos são nossos, numa tentativa de retomar a beleza e o ritmo da prosa narrativa:

a) "(...) que rostos mais coalhados, nossos rostos adolescentes em volta daquela mesa: o pai à cabeceira, o relógio de parede às suas costas, cada palavra sua ponderada pelo pêndulo, e nada naqueles tempos nos distraindo tanto como os sinos graves marcando as horas" (NASSAR, 1999, p.48-49).

b) "Que rostos mais coalhados, nossos rostos adolescentes em volta daquela mesa: o pai à cabeceira, o relógio de parede às suas costas, cada palavra sua ponderada pelo pêndulo, e nada naqueles tempos nos distraindo tanto como os sinos graves marcando as horas. ' $O$ tempo é 0 maior tesouro de que um homem pode dispor; embora inconsumível, o tempo é o nosso melhor alimento; sem medida que o conheça, o tempo é contudo nosso bem de maior grandeza: não tem começo, não tem fim; é um pomo exótico que não pode ser repartido, podendo entretanto prover igualmente a todo mundo; onipresente, o tempo está em tudo; existe tempo, por exemplo, nesta mesa antiga: existiu primeiro uma terra propícia, existiu depois uma árvore secular feita de anos sossegados, e existiu finalmente uma prancha nodosa e dura trabalhada pelas mãos de um artesão dia após dia; (...)" (Idem, p.53-54).

Numa leitura da intertextualidade com a tradição bíblica, nos trechos em destaque, é valorizada a concepção, desde o livro Eclesiastes, da "paciência na tribulação", assim como da voz do "pregador" - a voz que fala no livro como o Qohelet hebreu -, que se insurge contra a ordem como tradição, destacando-se a importância da experiência individual, o que é singular no conjunto de livros, de autorias e temporalidades diferenciadas que compõe a Bíblia. No livro Eclesiastes, tópico 9, destinado a "Prudência nas relações com as mulheres", é afirmado em tom de conselho imperativo: "Não frequentes o trato com a bailarina,/ nem a ouças,/ para que não suceda pereceres à força dos seus atrativos". Neste breve trecho bíblico, ressalta-se a aproximação com a prosa poética do romance, sendo o livro Eclesiastes um "paradigma da mistura de prosa e verso de variada 
metrificação (poikilómetron) desenvolvida pelo filósofo cínico Menipo de Gádara (Palestina, séculos IV-III a.C.)" (CAMPOS, 1990, p. 24).

Nessa relação de dialogismo entre tempos e culturas, clama nossa atenção o quanto Eclesiastes é um livro contraditório, que louva os prazeres do corpo, da comida, da bebida e da alegria compartilhada não apenas entre homens e mulheres unidos pelo casamento (CAMPOS, 1990, p. 19). Tais contradições, de forma sutil, estão presentes no modo como André vê a irmã e a descreve, num misto de atração incontrolável que deixa escapar, aqui e ali, avaliações que denunciam uma admiração perpassada por uma incontida censura moral - ela trazia a peste no corpo (NASSAR, 1999).

No entanto, há também neste momento da narrativa uma alegria potente que nos leva a Nietzsche, o "trágico é o poder das metamorfoses que pode transformar tudo em objeto de afirmação", concepção retomada por Gilles Deleuze em suas obras, como destaca Mário Bruno (2004, p. 10). No romance, no momento em que dança, Ana encarna o princípio da metamorfose, torna-se uma cópia "borrada", fora de foco, repete deformando tipos ou fantasmas de mulheres fatais, enquanto desenha, com os pés em fogo, o devir e o seu desafio à ordem. A irmã de André é descrita nesse episódio com marcas grotescas de uma aparência kitsch, um corpo movido pelo transbordamento ou pela duplicação de contornos, imagem rasurada, na recusa à simplicidade de campônia - é a borra gordurosa no lugar da boca, é a pinta de carvão acima do queixo, é a gargantilha de veludo roxo, é o pano murcho, a fresta escancarada dos seios num conjunto de incontida sensualidade.

\section{Rumor antigo}

$\mathrm{Na}$ cena da dança que desloca o centro, a cena retomada e ampliada evidencia os vestígios do moralismo paterno que deixa de ser a figura do pai para disseminar-se em valores de uma comunidade. O movimento frenético da dança (o desvoltar), a desestabilização dos centros (o lugar do pai, da família, da autoridade, enfim) faz com que o olhar de André se identifique, afinal, aos valores paternos que encontram eco no modo como admira Ana e, ao mesmo tempo, a censura. Tudo acontece como se Ana, a irmã desejada, houvesse transposto sozinha, com seu "deboche exuberante", os limites tênues que mantinham a sua 
vida numa ordem familiar em que não se admite o desperdício. Ao contrário de André, Ana é marcada pelo silêncio - a personagem pouco fala, é descrita e narrada pelo irmão. De forma surpreendente, nas últimas páginas do romance, tem-se a descrição de uma dança ao som da flauta, que ultrapassa os limites de um círculo e de seu centro.

Retomemos as palavras de Antonio Candido que afirma haver na literatura brasileira atual mais uma motivação para refletir:

(...) a ficção procurou de tantos modos sair das suas normas, assimilar outros recursos, fazer pactos com outras artes e meios, que nós acabamos considerando como obras ficcionalmente mais bem realizadas e satisfatórias algumas que foram elaboradas sem preocupação de inovar, sem vinco de escola, sem compromisso com a moda; inclusive uma que não é ficcional. Seria um acaso? Ou seria um aviso? Eu não saberia nem ousaria dizer. Apenas verifico uma coisa que é pelo menos intrigante e estimula a investigação crítica (CANDIDO, 1989, p. 215).

Nas reflexões críticas mais recentes, abandona-se a pretensão de atualidade ao definir-se a literatura como contemporânea. Ao retomarmos as palavras que problematizam o conceito, temos “(...) a literatura contemporânea não será necessariamente aquela que representa a atualidade, a não ser por inadequação, uma estranheza histórica que a faz perceber as zonas marginais e obscuras do presente, que se afastam de sua lógica" (SCHOLLHAMMER, 2009, p. 9-10). Procuramos, portanto, neste artigo, indagar por quais caminhos o romance Lavoura arcaica brilha (cada vez mais) na literatura brasileira contemporânea -, talvez por inadequação ou estranheza histórica. A linguagem da prosa atravessada pelo lirismo, por sua vez, enfatiza certa fluência próxima à oralidade, tão em cena nos primeiros momentos do Modernismo. Na década de setenta, 0 lirismo da linguagem do romance aponta uma "estranheza histórica" ou uma "inadequação", esgotado o gênero romance como representação e releitura do realismo.

Assassinada em plena dança, a bailarina atualiza antigas danças orientais e refaz outras perguntas: estaria o Ocidente metaforicamente na figura do próprio pai marcado pela repulsa, culpa e morte? Como um pai poderia sobreviver após assassinar a própria filha? E seria a culpa desse pai uma resposta à infância dos filhos, parafraseando os versos do poeta Jorge de Lima? O espanto final, a morte de Ana, o sofrimento diante de um acontecimento irreparável, desperta a surpresa e a quebra de certa expectativa, pois o desdobramento do romance nos leva a 
imaginar que o final fatídico estaria mais próximo de André. $O$ acontecimento trágico une os fios da trama e elabora os elos com um mundo antigo cujo eco pode ser ouvido desde a Grécia Antiga, ao tentar exprimir o irrepresentável: a morte. A planta da infância, afinal, encontra seu rumor antigo.

\section{Referências bibliográficas}

AGAMBEN, Giorgio. Infância e história. Destruição da experiência e origem da história. Trad. Henrique Burigo. Belo Horizonte, Minas Gerais: Ed.UFMG, 2008.

ALTER, Robert; KERMODE, Frank (Org.). Guia literário da Bíblia. Trad. Raul Filker. São Paulo : Fund. Ed.da Unesp, 1997.

ARTAUD, Antonin. O teatro e seu duplo. Trad. Teixeira Coelho. São Paulo: Martins Fontes, 2006.

BíBLIA SAGRADA. Trad. da Vulgata Pe. Matos Soares. São Paulo: Paulinas, 1987.

BOSI, Alfredo. História concisa da literatura brasileira. São Paulo: Cultrix, 1999.

BRUNO, Mário. Lacan \& Deleuze. 0 trágico em duas faces do além do princípio do prazer. Rio de Janeiro: Forense Universitária, 2004.

CAMPOS, Haroldo de. Qohélet $\mathbf{0} \mathbf{0}$ que sabe: Eclesiastes: poema sapiencial. São Paulo: Perspectiva, 1990.

CANDIDO, Antonio. A educação pela noite e outros ensaios. São Paulo: Ática, 1989.

NASSAR, Raduan. Lavoura arcaica. São Paulo: Cia. das Letras, 1999.

REIS, Carlos; LOPES, Ana Cristina M. Dicionário de narratologia. Coimbra : Livraria Almedina, 1996.

REUTER, Yves. A análise da narrativa - o texto, a ficção e a narração. Trad. Mario Pontes. Rio de Janeiro: DIFEL, 2002.

SARDUY, Severo. Barroco. Trad. Maria de Lurdes Júdice e José Manuel de Vasconcelos. Lisboa: Vega, s/d.

SCHOLLLHAMER, Karl Erik. Ficção brasileira contemporânea. Rio de Janeiro: Civilização Brasileira, 2009.

SOUZA, Jacqueline Ribeiro de. Discurso e subjetividade em Lavoura arcaica. Dissertação de Mestrado apresentada ao Programa de Pós-graduação em Letras: 
Estudos literários, da Universidade Federal de Montes Claros. http://www.cch.unimontes.br/ppgl/admin/arquivos_upload/banco_dissertacoes/66. pdf. Acesso em 23/04/2013.

STALLONI, Yves. Os gêneros literários. A comédia, o drama, a tragédia, o romance, a novela, os contos. A poesia. Trad. Flávia Nascimento. Rio de Janeiro: DIFEL, 2001.

SÜSSEKIND, Flora. Literatura e vida literária. Polêmicas, diários \& retratos. Minas Gerais: Ed.UFMG, 2004. 
Artigo recebido em: 15 de maio de 2014

Artigo aprovado em: 17 de julho de 2014

\section{Sobre a autora:}

Iza Quelhas possui graduação em Letras pela Universidade Federal Fluminense (UFF), mestrado e doutorado em Letras (Ciência da Literatura) pela Universidade Federal do Rio de Janeiro (UFRJ). Atualmente é Professora Associada da Universidade do Estado do Rio de Janeiro, na Faculdade de Formação de Professores. Integra o corpo docente do Mestrado em História Social (PPGHSUERJ). Possui experiência acadêmica na área de Letras, com ênfase em Literatura Brasileira, Teoria da Literatura e Literaturas em Língua Portuguesa. Sua pesquisa é direcionada aos estudos de literatura, história e cultura, linguagens e identidades. É autora dos livros: A passagem dos sinais (1996), poemas, publicado pela EDUFF; Os laranjais abandonados e outras histórias (2005), contos, publicado pela Fábrica de Livros (RJ). 